\title{
Aquicultura na Região de Laranjeiras do Sul, PARANá: diagnóstico e POLÍticas PÚBLICAS
}

\author{
Aquaculture in the Region OF LaRanjeiras do Sul, Paraná: diagnosis and PUblic \\ POLICY
}

Acuicultura em la Región de Laranjeiras do Sul, PARAná: diagnóstico y POlíticas PÚBLICAS

\author{
André de Moura Victorio ${ }^{1}$ \\ https://orcid.org/0000-0001-6556-3988 \\ Dayane Regina Lenz ${ }^{2}$ \\ https://orcid.org/0000-0002-5914-7782 \\ Emmanuel Arnhold ${ }^{3}$ \\ https://orcid.org/0000-0003-0922-146X \\ Betina Muelbert ${ }^{4}$ \\ https://orcid.org/0000-0001-6930-9231
}

Submissão: 30/12/2020 / Aceito: 10/03/2021 / Publicado: 30/06/2021.

\begin{abstract}
Resumo
Aquicultura tem crescido constantemente no Brasil e no Paraná, apresentando-se como oportunidade de diversificação da produção rural e geração de renda, sem aumento de mão de obra. No entanto, a atividade está pouco estruturada, com poucos estudos realizados sobre sua situação, viabilidade e caminhos para o desenvolvimento sustentável na região estudada. Objetivou-se com este trabalho diagnosticar a situação da aquicultura na região geopolítica de Laranjeiras do Sul - Paraná. A pesquisa é um estudo transversal descritivo baseado em entrevistas com questionário semiestruturado in loco em todas as entidades envolvidas no setor aquícola e em amostra aleatória de 70 de 190 aquicultores existentes, proporcionalmente, nos dez municípios avaliados. Dados foram submetidos ao teste quiquadrado, nos softwares R e Sphinx. Entre entidades, observou-se que a maioria desconhece a cadeia, realizou projetos pontuais e sem continuidade, mas consideram alto o potencial de desenvolvimento. A maioria das políticas públicas até o momento buscaram apoiar o aquicultor na assistência técnica e construção de viveiros. O foco da produção apontou a venda direta e autoconsumo, havendo abate informal. Propriedades são majoritariamente pequenas, com outra atividade como principal, pequena lâmina de água, mão de obra predominantemente familiar e chefiadas por homens. A produção principal é de tilápia em policultivo semi-intensivo. Parte significativa relatou problemas na venda e entrega produção diretamente ao consumidor. Conclui-se que os principais problemas são: acesso a mercados, falta de abatedouros ou frigoríficos regularizados e assistência técnica. Considera-se que, solucionandose estes, a aquicultura na região tem potencial de crescimento e pode representar forma de diversificação. Palavras-chave: Cadeia aquícola; Desenvolvimento regional; Diagnóstico; Piscicultura.
\end{abstract}

\footnotetext{
${ }^{1}$ Mestre em Agroecologia e Desenvolvimento Rural Sustentável. Extensionista rural no Instituto de Desenvolvimento Rural do Paraná IAPAR-EMATER (IDR-Paraná). E-mail: amvictorio@idr.pr.gov.br

${ }^{2}$ Mestra em Ciência Animal. Extensionista rural no Instituto de Desenvolvimento Rural do Paraná IAPAR-EMATER (IDR-Paraná). E-mail: drlenz@idr.pr.gov.br

${ }^{3}$ Doutor em Genética e Melhoramento. Professor Associado II na Universidade Federal de Goiás (UFG)/Programa de Pós-graduação em Ciência Animal e Zootecnia. E-mail: emmanuelarnhold@ yahoo.com.br

${ }^{4}$ Doutora em Engenharia da Produção/Gestão Ambiental. Professora na Universidade Federal da Fronteira Sul (UFFS), Campus de Laranjeiras do Sul/Programa de Pós-graduação em Agroecologia e Desenvolvimento Rural Sustentável. Email: betina.muelbert@uffs.edu.br
} 


\begin{abstract}
Aquaculture has been growing steadily in Brazil and Paraná, presenting itself as an opportunity to diversify rural production and generate income, without increase in labor. The activity is poorly structured, with few surveys on its situation, viability and pathways to sustainable development about the researched area. The objective of this study was to diagnose aquaculture in the geopolitical region of Laranjeiras do Sul - Paraná. The research is a descriptive cross-sectional study based on interviews with semi-structured questionnaire in loco with all the entities involved in aquaculture and with a random sample of 70 out of 190 aquaculture producers, proportionally, in the ten municipalities evaluated. Data were submitted to chi-square test, through software R and Sphinx. Among entities, most did not seek knowledge of the chain and carried out sporadic and discontinuous projects but found out as high development potential. Most of the public policy realized so far aimed to support with technical assistance and fish pond construction. Regional production focuses to direct sales and self-consumption, existing informal slaughter. Properties are mostly small, with other main activity, little water extension, predominantly family labor, managed by men. Main production is semi-intensive polyculture system with tilápia. Significant portion reported problems in trade and outflow production directly to the consumer. It is concluded that aquaculture main problems are: access to markets, lack of slaughterhouses and technical assistance. It's considered that with the resolution of these problems aquaculture has potential to grow and may represent interesting diversification production option.
\end{abstract}

Keywords: Aquaculture chain, Regional development, Diagnosis, Fish farming.

\title{
Resumen
}

Acuicultura ha crecido constantemente en Brasil y Paraná, presentándose como una oportunidad para diversificar la producción rural y generar ingresos. Sin embargo, la actividad está mal estructurada, con pocos estudios realizados sobre su situación, viabilidad y caminos hacia el desarrollo sostenible en la región estudiada. El objetivo de este trabajo fue diagnosticar la situación de la acuicultura en la región geopolítica de Laranjeiras do Sul - Paraná. Este es un estudio descriptivo transversal basado en entrevistas in loco con todas las entidades involucradas y una muestra aleatoria de 70 de 190 acuicultores existentes, proporcionalmente, en diez municipios. Los datos se sometieron a la prueba de chi-cuadrado, utilizando software R y Sphinx. Entre las entidades, se observó que la mayoría desconoce la cadena, realiza proyectos puntuales y sin continuidad, pero considera alto el potencial de desarrollo. La mayoría de las políticas públicas han buscado apoyar a la acuicultura en la asistencia técnica y la construcción de viveros. La producción se centró en la venta directa y autoconsumo, con sacrificio informal. Las propiedades son principalmente pequeñas, con otra actividad como primario, poca cantidad de agua, predominantemente mano de obra familiar y encabezada por hombres. La principal producción es la tilapia en policultivo semi-intensivo. Una parte significativa informó problemas para vender y entrega la producción directamente al consumidor. Se concluye que los principales problemas son: acceso a los mercados, falta de mataderos regulares y asistencia técnica. Al resolver estos, acuicultura tiene potencial de crecimiento y puede representar una forma de diversificación.

Palabras llave: Cadena de acuicultura; Desarrollo regional; Diagnóstico; Piscicultura. 


\section{INTRODUÇÃO}

A aquicultura, que é a criação ou cultivo de organismos aquáticos, tem apresentado crescimento de produção e mercado no mundo todo. O Brasil e especialmente o estado do Paraná refletem esse crescimento. As taxas anuais de incremento da produção de organismos aquáticos ficam em torno de $10 \%$ ao ano e o país já atinge 507,1 mil toneladas, superando o volume da pesca extrativa. A expectativa é que a produção brasileira dobre de volume até o ano de 2030 (FAO, 2018). O Paraná é o terceiro maior estado produtor com 17,6\% do pescado de aquicultura brasileiro, totalizando 98.512 toneladas (PARANÁ, 2018a). Quando se considera somente a piscicultura, o estado apresenta a maior produção do Brasil, com foco na tilápia (PEIXE BR, 2019). No entanto, 66\% do volume da piscicultura está concentrado na região oeste do Paraná (PARANÁ, 2018b), observando-se carência nas demais regiões, onde a produção é menor e menos estruturada.

A piscicultura é uma possibilidade de diversificação da pequena propriedade familiar devido à sua alta produtividade, melhorias nas condições de segurança alimentar, diminuição da pobreza e promoção do desenvolvimento social e econômico, até mesmo em locais que apresentam restrição hídrica (LIMA et al., 2018). A aquicultura gera mais renda por hectare que a agricultura, possui cadeia produtiva mais complexa, maior impacto social em sua industrialização. As repercussões de cadeias de pequenas propriedades aquícolas são mais relevantes quando comparadas a grandes redes deste setor (FILIPSKI; BELTON, 2018).

A região de Laranjeiras do Sul encontra-se inserida no Território Cantuquiriguaçu, na qual a agropecuária é responsável pela terceira maior geração de empregos, quinta maior geração de produção e sétima maior geração de renda (CANQUERINO et al., 2015). Observa-se que 45,7\% da população da região ainda ocupa o meio rural, predominantemente em pequenas e médias propriedades de base familiar (71,6\%), com produção voltada para o cultivo de grãos, bovinocultura, avicultura e suinocultura (IPARDES, 2018).

Políticas públicas voltadas para a aquicultura podem transformar a atividade em importante fonte de renda, de forma sustentável. Isso implica no conhecimento da realidade local para que sejam inseridas ações adequadas aos interesses dos produtores (DOS SANTOS et al., 2014). A viabilidade da cadeia aquícola como um todo deve ser avaliada, pois o incentivo a uma produção que não tem respaldo comercial e disponibilidade de insumos gera consequências danosas, em especial aos pequenos produtores (DUTRA et al., 2014; RAMOS et al., 2018; RIBEIRO-NETO et al., 2016). 
Levando-se em conta a escassez de estudos sobre a cadeia aquícola na região central do Paraná, objetivou-se com esse trabalho elaborar um diagnóstico detalhado da aquicultura na região geopolítica de Laranjeiras do Sul: situação atual, políticas públicas e perspectivas. Com informações quanto à caracterização da atividade produtiva, é possível ter bases mais sólidas para o desenvolvimento de políticas públicas eficientes voltadas ao setor, respeitando as especificidades regionais.

\section{MÉTODO}

Este é um estudo qualitativo-quantitativo transversal descritivo realizado no período de novembro de 2017 a maio de 2018, na região geopolítica de Laranjeiras do Sul - Estado do Paraná. A região é composta pelos municípios de Diamante do Sul, Espigão Alto do Iguaçu, Guaraniaçu, Laranjeiras do Sul, Marquinho, Nova Laranjeiras, Porto Barreiro, Quedas do Iguaçu, Rio Bonito do Iguaçu e Virmond (Figura 1). Foram percorridos $3.062 \mathrm{~km}$ durante a pesquisa de campo para a realização das entrevistas in loco, nas propriedades e entidades.

Figura 1 - Mapa da região geopolítica de Laranjeiras do Sul, Paraná

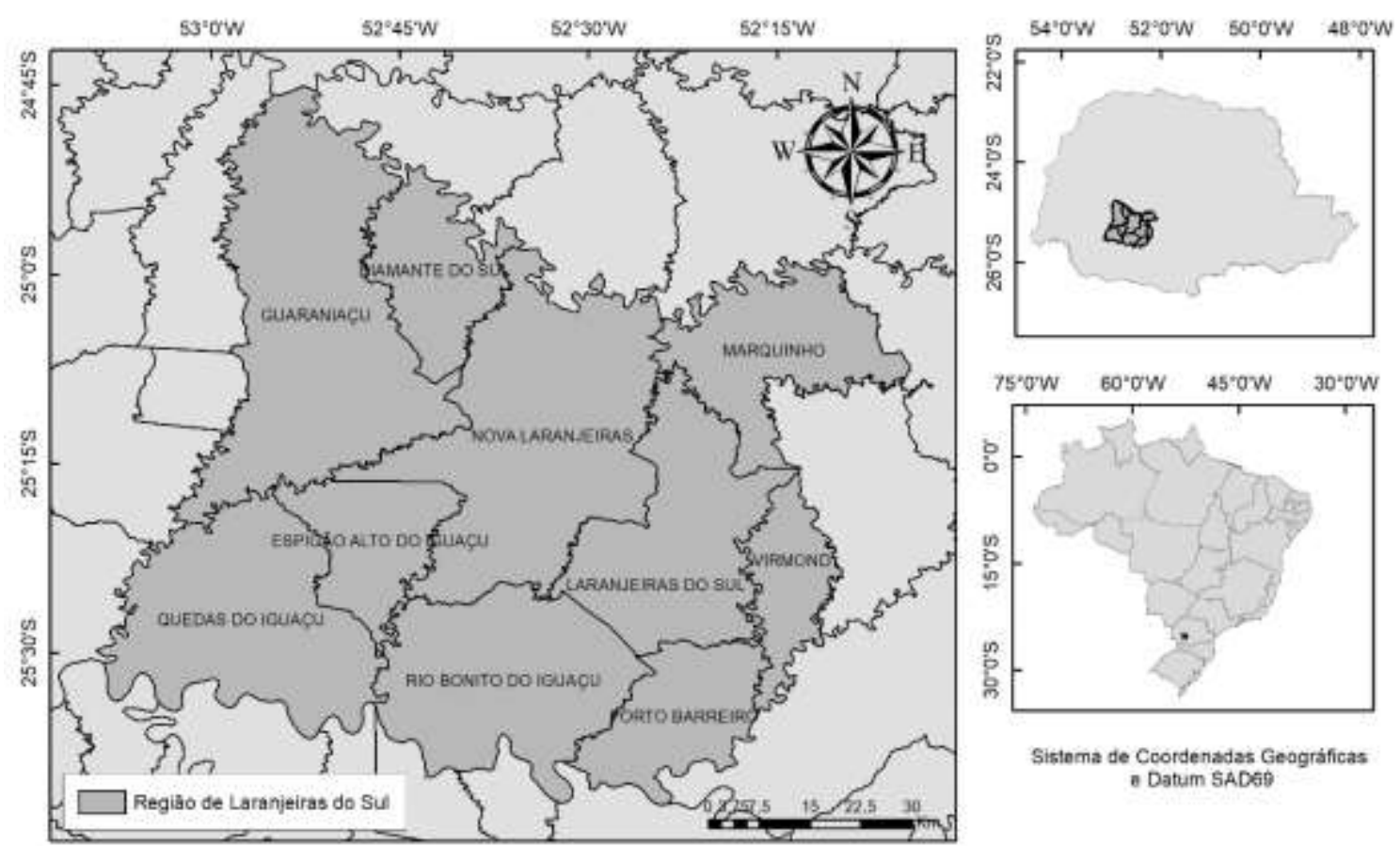

Fonte: Elaborado pelo autor (2018).

Foi realizado levantamento bibliográfico e pesquisa de campo, esta última dividida em duas etapas. A primeira etapa foi a realização de um questionário semiestruturado junto às entidades de 
assistência técnica, entidades associativas e cooperativas que tivessem ligação com a cadeia produtiva do pescado e órgãos públicos. Com base nessas informações, foi realizada a segunda etapa, que se deu por meio de entrevistas com produtores rurais, também guiado por questionário semiestruturado. As entidades visitadas estão descritas na tabela 1.

\section{Tabela 1 - Entidades entrevistadas na primeira etapa da pesquisa a campo}

\begin{tabular}{lc}
\hline \multicolumn{1}{c}{ Identificação } & Total \\
\hline Unidade Municipal do Emater* & 10 \\
Unidade Regional da Emater** & 1 \\
Prefeitura ou Secretaria Municipal de Agricultura & 10 \\
Sindicato Rural & 1 \\
Associação de aquicultores & 2 \\
Frigorífico com Serviço de Inspeção Municipal- & 2 \\
SIM/POA & \\
Cooperativa & 1 \\
Assistência privada & 2 \\
SEBRAE** & 1 \\
Associação de municípios & 1 \\
Universidades & Total
\end{tabular}

Fonte: Elaborado pelo autor (2019). *Instituto Paranaense de Assistência Técnica e Extensão Rural. **Serviço Brasileiro de Apoio às Micro e Pequenas Empresas.

Nas entrevistas com as entidades foi realizada a identificação dos produtores de pescado existentes em bancos de dados, cadastros e outras fontes formais ou informais, que tiveram seus nomes compilados em uma listagem simples. A partir desta, foi sorteada aleatoriamente uma amostragem de $30 \%$ proporcional à quantidade de produtores em cada município, margem superior ao utilizado comumente para garantir a confiabilidade dos resultados. Foram sorteados aleatoriamente 70 produtores rurais, de população identificada de 190 aquicultores, distribuídos proporcionalmente à quantidade de estabelecimentos por município. Os dados da amostragem estão na tabela 2.

Importante ressaltar que, como as informações fornecidas pela maioria dos entrevistados foram baseadas em conhecimento pessoal e não por metodologia de pesquisa científica, os dados apresentaram variação até entre entidades de um mesmo município, por isso a listagem foi feita de maneira que compilasse todos os dados obtidos. Mesmo com essa medida de redução do erro, observou-se nas visitas a campo que parte dos produtores são desconhecidos das entidades entrevistadas. 
Tabela 2 - Produtores de pescado identificados, por município avaliado e a amostragem utilizada

\begin{tabular}{lcc}
\hline \multicolumn{1}{c}{ Município } & Total de produtores* & Total de entrevistados \\
\hline Diamante do Sul & 18 & 6 \\
Espigão Alto do Iguaçu & 8 & 4 \\
Guaraniaçu & 23 & 7 \\
Laranjeiras do Sul & 20 & 8 \\
Marquinho & 10 & 4 \\
Nova Laranjeiras & 15 & 8 \\
Porto Barreiro & 31 & 10 \\
Quedas do Iguaçu & 41 & 13 \\
Rio Bonito do Iguaçu & 12 & 6 \\
Virmond $\quad 12$ & 4 \\
\multicolumn{1}{c}{ Total } & $\mathbf{1 9 0}$ & $\mathbf{7 0}$ \\
\hline
\end{tabular}

Fonte: Elaborado pelo autor (2019). *Dados informados pelas entidades em entrevista.

Os questionários utilizados foram elaborados com a finalidade de estabelecer as características da cadeia produtiva regional e suas inter-relações. Nas entrevistas com as entidades foram abordados temas relativos às ações já realizadas, em andamento ou planejadas para atender à cadeia aquícola regional. Com relação às propriedades rurais, o questionário abordou aspectos pessoais dos responsáveis, dados gerais da propriedade e uma caracterização básica da atividade aquícola.

Os dados foram analisados através da distribuição de frequências, intervalos de confiança, teste qui-quadrado e elaboração de tabelas e gráficos. Foi utilizado o software R (R Core Team, 2018) e o software Sphinx Survey®. Todas as atividades foram aprovadas pelo Comitê de Ética em Pesquisa da Universidade Federal da Fronteira Sul - CEP/UFFS (protocolo CAAE: 83488618.6.0000.5564/2018).

\section{RESULTADOS E DISCUSSÃO}

Durante a primeira etapa da pesquisa, em que foram visitadas as entidades e organizações presentes na cadeia da aquicultura local, sendo vinte e duas públicas e dez privadas, observou-se que há pouco engajamento na atividade, especialmente por não haver na região todos os elos necessários ao setor. Sete elos são considerados fundamentais numa cadeia de produção: fazendas aquícolas de alevinagem e engorda; indústrias de ração e premix; empresas de equipamentos; plantas de abate e processamento de pescado; cooperativas e associações de produtores; setores de gestão e organização (ensino, apoio, pesquisa e extensão); instituições de crédito e fomento (FEIDEN et al., 2018). 
Alguns dos municípios investigados já realizaram ações de fomento à atividade, que não apresentaram continuidade, como contratos temporários de assistência técnica, incentivos à construção de viveiros, entre outras. Este é um agravante para o desenvolvimento do setor, pois após o incentivo inicial proveniente do setor público, ocorreu a implantação de diversos empreendimentos que não encontraram respaldo após iniciar seu funcionamento, pois não conseguiram acessar mercados consumidores. Alguns deixaram a atividade, e os que continuaram apresentam-se receosos de novos investimentos sem a garantia de políticas de longo prazo.

Fica claro que a atividade não tem atraído atenção das entidades já que $96,3 \%$ dos entrevistados não sabem a produção estimada de pescado do município e 88,9\% não sabem informar uma estimativa da área de produção existente ou realizou pesquisas sobre o setor. Para se estimar a quantidade de produtores, 59,3\% dos entrevistados basearam-se em aproximações pessoais, e somente $11 \%$ fizeram algum levantamento formal das informações. A única exceção foi o município de Porto Barreiro, que mantém um banco de dados da produção aquícola municipal.

Do ponto de vista das entidades entrevistadas, quanto ao destino da produção, $53 \%$ citaram o autoconsumo, $22 \%$ a venda para semana santa católica, $16 \%$ a venda em feiras e somente $9 \%$ indicaram a venda para frigoríficos. Na figura 2 estão alguns dos resultados mais relevantes da primeira etapa da pesquisa.

Apesar de $100 \%$ dos entrevistados considerarem que a aquicultura tem importância baixa ou nula, $74 \%$ acredita que a atividade tem alto potencial de crescimento. Com relação à mão de obra disponível entre as entidades entrevistadas, $37 \%$ não possui profissionais na área e 55,6\% possui somente um, e este também atua em outras atividades produtivas vegetais e animais. Em parte, a pouca atenção dada à aquicultura tem como uma das causas a atividade ser relativamente recente (51,9\% atuam em aquicultura há menos de cinco anos), se comparada com o tempo de profissionalização dos outros tipos de produção rural praticadas na região. 
Figura 2 - A) Atividades realizadas pelas entidades entrevistadas. B) Caracterização da instituição. C) Conhecimento dos dados de produtores regionais. D) Foco da produção local de pescados. E) Importância da aquicultura na economia e sociedade local, de acordo com os entrevistados. F) Potencial de crescimento da aquicultura, de acordo com os entrevistados

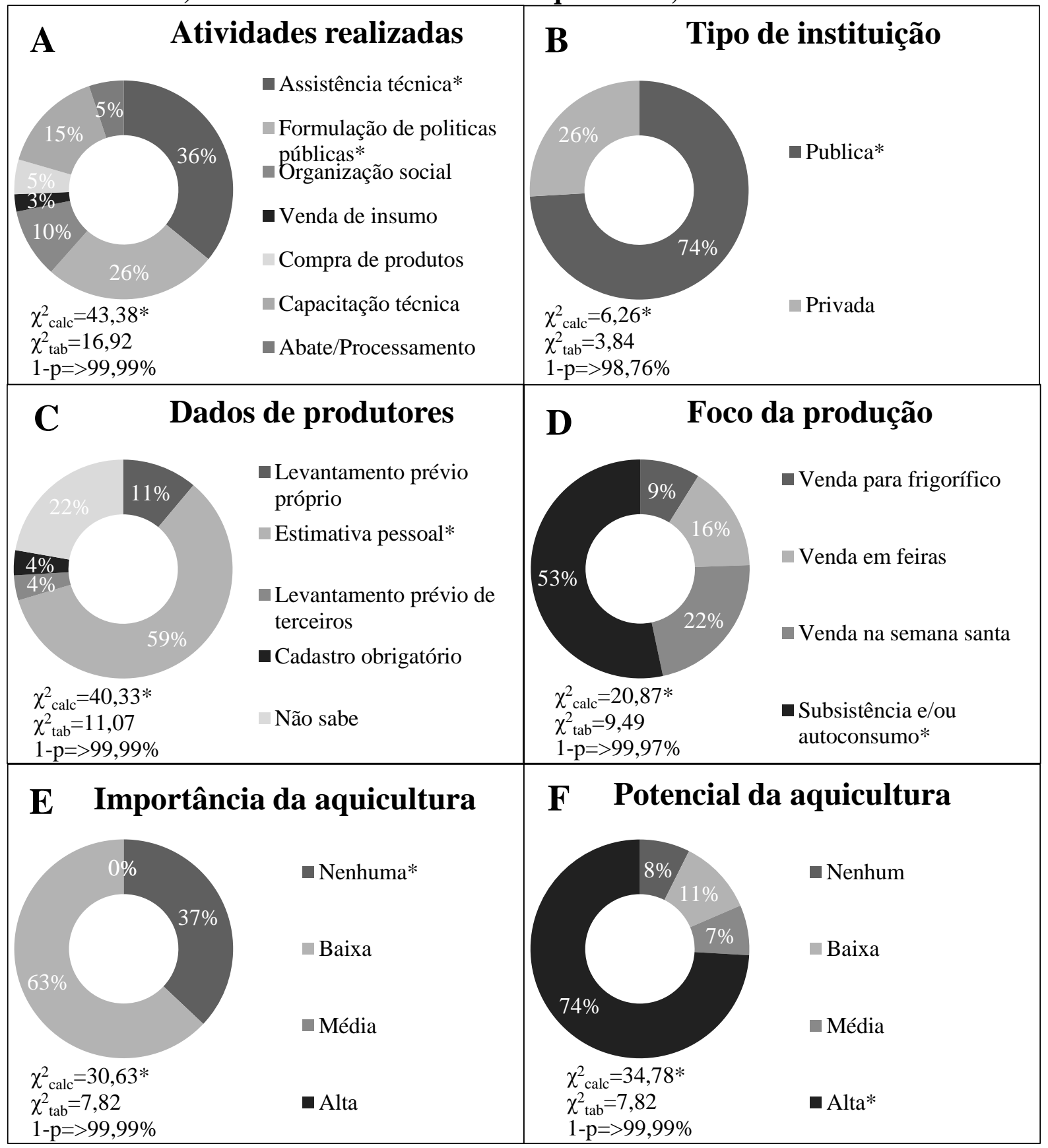

*Resultado diferente, $\mathrm{p}<0,05$.

Houve vários projetos realizados na região, principalmente no apoio à abertura de viveiros, assistência técnica e compra de alevinos. A evolução dos projetos apresentados na tabela 3 mostra que inicialmente ocorreu o investimento em assistência técnica e apoio na abertura de viveiros. 
Com o tempo, o apoio com maquinários para abertura de viveiros foi diminuindo, em parte devido à maior criteriosidade por parte dos órgãos ambientais fiscalizadores. $\mathrm{O}$ aumento no número de entidades que não têm projetos para o futuro mostra que a aquicultura não está entre as atividades prioritárias na região, apesar de todos a considerarem com potencial de crescimento. Poucas alterações nos projetos em andamento estão previstas, e alguns projetos serão descontinuados. Nenhuma das ações até o momento buscou fortalecer a cadeia como um todo, sendo percebido como um dos principais problemas por boa parte dos entrevistados a dificuldade de comercialização.

Tabela 3 - Projetos realizados pelas entidades entrevistadas, voltados à aquicultura

\begin{tabular}{lccc}
\hline \multirow{2}{*}{\multicolumn{1}{c}{ Projetos }} & \multicolumn{2}{c}{ Frequência das respostas } \\
\cline { 2 - 4 } & Finalizados & Atuais & Futuros \\
\hline Não possui & 6 & 5 & $13^{*}$ \\
Levantamento de informações & 0 & 4 & 0 \\
Apoio técnico & $10^{*}$ & $13^{*}$ & 7 \\
Apoio com maquinário & $8^{*}$ & 3 & 1 \\
Projetos financeiros & 1 & 2 & 0 \\
Não se aplica & 2 & 2 & 2 \\
Organização de evento temático & 2 & 3 & 1 \\
Organização de compra e venda de insumos & 1 & 4 & 4 \\
Compra e revenda de pescado & 1 & 1 & 1 \\
Capacitação técnica & 3 & 1 & 0 \\
Compras institucionais (PNAE) & 1 & 0 & 2 \\
Frigorífico privado ou com apoio público & 2 & 0 & 8 \\
\hline
\end{tabular}

*Resultados diferentes para $\chi^{2}$ na mesma coluna, $\mathrm{p}<0,05$. PNAE - Programa Nacional de Alimentação Escolar.

Uma informação importante levantada é quanto às formas de abate do pescado produzido na região. A maioria $(70,4 \%)$ apontou que existe abate informal de pescado por produtores, seguido por abates informais em pesque-pagues (37\%), abatedouro inspecionado (18,5\%) e somente um entrevistado $(3,4 \%)$ desconheceu que exista forma de abate na região. Foi citado por 52,5\% dos entrevistados que o maior problema a ser resolvido é a dificuldade de abate formal e a abertura de um canal de comercialização.

A formalização e estruturação desses empreendedores que já abatem e comercializam informalmente pode ser o caminho mais rápido para viabilizar a cadeia do pescado na região, considerando que o volume comercializado através das feiras é pouco expressivo e esporádico, com pico de vendas no período da quaresma, intensificado durante a semana santa católica que antecede a páscoa. 
O consumo sazonal baseia-se em questões religiosas, característica cultural da região observada. Em Laranjeiras do Sul foram apresentados dados de consumo que confirmam esse aumento sazonal do consumo de pescado. Apesar de haver mercado consumidor local considerável, há grande dependência de pescado inspecionado advindo de outras regiões (GLOWKA et al., 2018). A presença de abatedouros ou frigoríficos de baixa capacidade é muito importante para o desenvolvimento regional, estes podem formar um arranjo produtivo de governança em redes e exercer grande influência na estruturação da cadeia como um todo (CHIDICHIMA et al., 2018).

Outra oportunidade de médio a longo prazo seria a formação de organização associativa ou cooperativa para pleitear a estruturação de abatedouro ou frigorífico com apoio governamental. Uma ação como essa necessita de capacitação dos associados quanto à estrutura organizacional da produção, processo de abate, entre outros temas importantes para o sucesso do empreendimento. Existem casos de sucesso na região oeste do Paraná com sistema de integração (BRUM; AUGUSTO, 2015), mas há outras formas de cooperativas, que podem fornecer importante apoio e funcionam de maneira adaptada a cada caso (ALMEIDA et al., 2016; FONSECA et al., 2017).

Os dados levantados nas entrevistas com aquicultores são compatíveis com o perfil das propriedades rurais na região (COELHO; PAULA, 2018). Estas podem ser classificadas no que se denomina agricultura familiar em sua estrutura mais tradicional, as famílias de produtores são majoritariamente comandadas por homens $(94,3 \%)$, casados ou em união estável (94,3\%), com dois a três filhos $(61,4 \%)$ e de escolaridade do responsável até o ensino fundamental completo $(41,4 \%)$. Quanto à renda familiar, a maioria relatou obter três ou mais salários mínimos mensais (62,8\%), que se aproxima do PIB per capita médio do Paraná (IPARDES, 2018). Somente 11,4\% dos avaliados relatou que todos os membros da família possuem renda originada fora da propriedade.

O apoio dos filhos está presente sem remuneração em 31,4\% das propriedades avaliadas. Na aquicultura, assim como nas atividades rurais, observou-se que a sucessão familiar também está sendo um problema, pois 51,4\% dos entrevistados que tem filhos maiores de idade, viram seus descendentes deixarem o meio rural. O Paraná apresenta taxas de migração urbana dos jovens menores que a média do Brasil (DELGADO et al., 2016).

Em revisão bibliográfica realizada por Gris, Lago, Brandalise (2017), a maior parte dos artigos que tratam sobre sucessão familiar destacam a renda como fator limitador na permanência do jovem no campo, além da infraestrutura do campo, acesso à educação, políticas públicas, desigualdade de gênero e visão negativa dos pais quanto ao futuro na propriedade. São apontadas como possíveis estratégias para a fixação do jovem no campo através do incremento de renda a 
pluriatividade e a diversificação da produção, ponto em que a aquicultura pode inserir-se. No entanto, deve-se destacar que a decisão de sair ou ficar na propriedade é muito mais complexa, com influência de fatores externos e internos à propriedade, questões pessoais e socioculturais, pontuadas oportunamente por Matte et al. (2019) e Matte e Machado (2016).

As propriedades com viveiros de peixes entrevistadas são majoritariamente pequenas, de tamanho entre 10 e 15 hectares (27\%), têm como atividade produtiva primária geradora de renda a produção de leite (36\%). Esses dados são corroborados em parte por outros trabalhos já realizados no Paraná (DUTRA et al., 2014) quanto às características de tamanho das propriedades da região. Com relação ao crédito rural, a maioria dos entrevistados já utiliza crédito de custeio ou investimento (50\%) e não relata problemas no processo de aquisição (72,9\%). Esse dado é importante, pois mostra que o custo não seria a principal dificuldade para o investimento em aquicultura. A mão de obra utilizada na maior parte das propriedades é familiar $(65,5 \%)$ e, considerando que a aquicultura inicialmente pode ser desenvolvida como forma de diversificação da produção sem grande acréscimo no tempo já dispendido em outras atividades, a produção de pescado não traria aumento de custos com funcionários.

Um problema a se considerar é que a maior parte dos entrevistados não faz qualquer controle econômico ou administrativo das atividades (42,9\%), isso dificulta a avaliação da eficiência e lucratividade de qualquer que seja a atividade produtiva realizada. O conhecimento dos produtores com relação aos impactos ambientais mostrou-se limitado ao transmitido em canais de rádio e televisão $(72,9 \%)$, e a maioria não conhece (38\%) ou não tem interesse numa forma de produção agroecológica (40\%). As principais informações quanto às características das propriedades podem ser vistas na figura 3. 
Figura 3 - A) Tamanho total da propriedade. B) Atividade produtiva principal na propriedade. C) Crédito rural. D) Dificuldades para acesso ao crédito. E) Mão de obra utilizada na propriedade. F) Controle financeiro administrativo das atividades realizadas

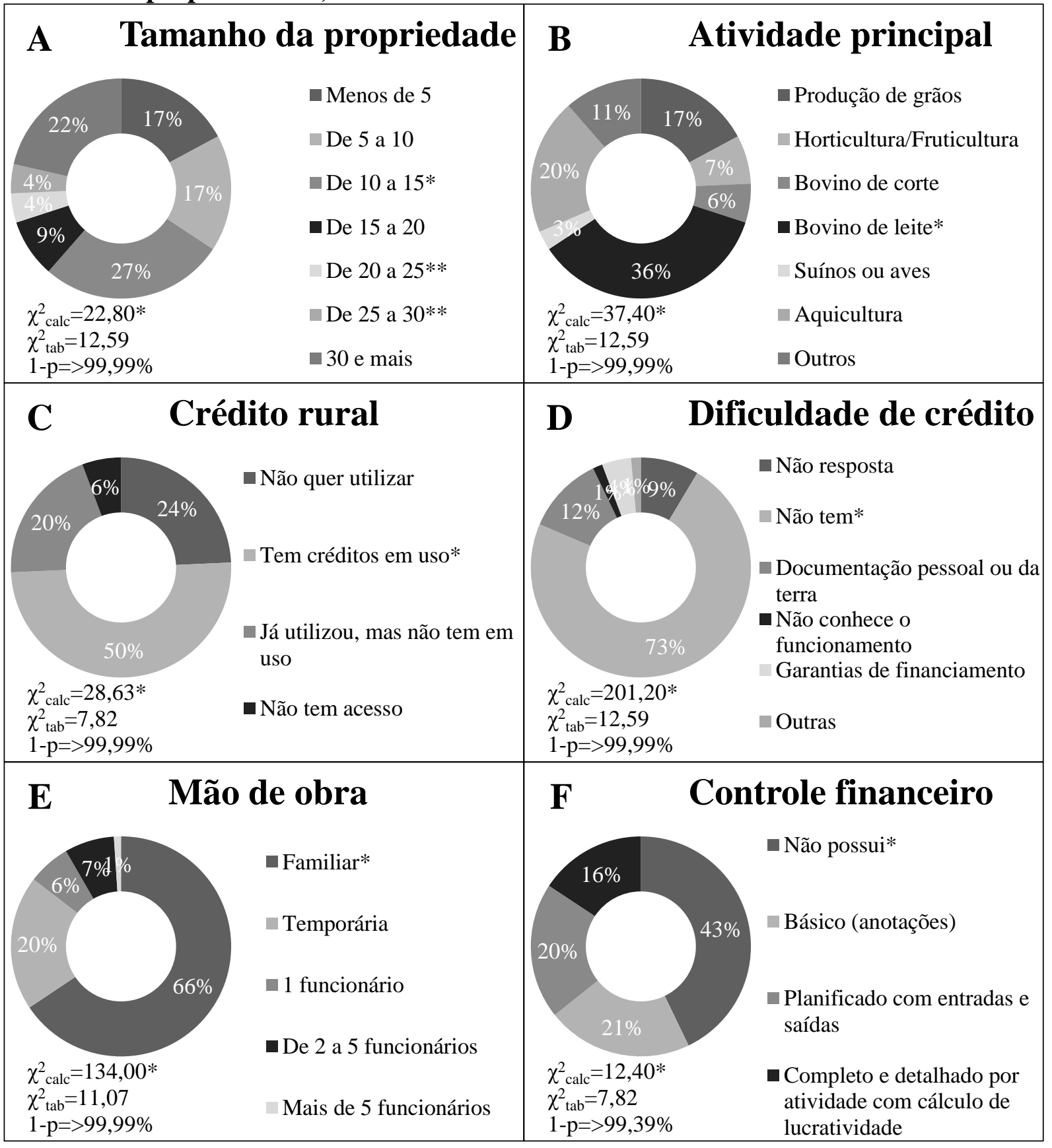

*Resultado diferente, $\mathrm{p}<0,05$.

A última parte da pesquisa foi voltada ao levantamento do perfil das unidades produtivas aquícolas. Observou-se que há predominância da criação de peixes, com algumas ações pontuais na criação de camarão de água doce, alavancadas pela Universidade Federal da Fronteira Sul através 
de projetos de pesquisa e extensão. De maneira geral, a produção de camarão não se mostrou significativa.

A maioria das pisciculturas tem menos de $6.000 \mathrm{~m}^{2}$ de lâmina de água (62\%), dividida em dois a quatro (34\%) ou quatro a seis viveiros $(31 \%)$, que não sabem quanto produzem ou produzem menos de um ciclo ao ano (57\%). As principais espécies presentes nas pisciculturas foram a tilápia $(95,7 \%)$ e as carpas $(81,4 \%)$, na maioria das vezes em sistemas de policultivo semi-intensivo (58\%), integrada ou não às outras atividades produtivas realizadas, e a estrutura mais comum é de viveiros escavados $(97,1 \%)$. Dados apresentados graficamente nas figuras 4 e 5 .

\section{Figura 4 - Principais espécies cultivadas}

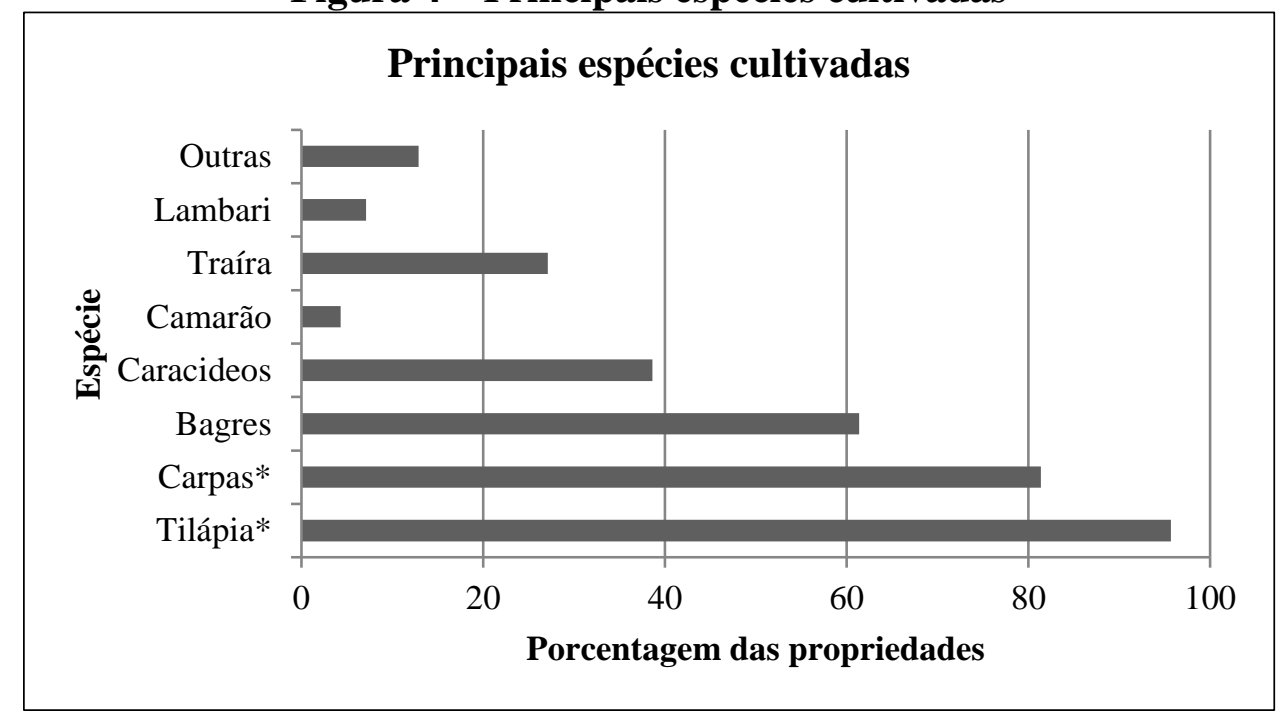

$*$ Resultado diferente, $\mathrm{p}<0,05$.

A assistência técnica recebida pelos piscicultores da região é prioritariamente pública (32\%), mas a maior parte relata nunca ter recebido assistência (53\%). Apesar de uma pequena parte não ter interesse em capacitação técnica $(11 \%)$, a maioria tem interesse e nunca teve oportunidade de fazer algum curso na área $(37 \%)$.

Um indicador do grau de tecnificação foi a utilização de equipamentos e o tipo de alimentação. Os dados mostraram que já existe algum grau de tecnificação, pois a maioria utiliza ração comercial como única fonte alimentar (57\%), mas não utiliza densidades altas de produção, que geram risco de mortalidade e o consequente uso de equipamentos diversos, pois $91,4 \%$ dos piscicultores não possui aeradores ou alimentadores.

Em sistemas menos intensivos, a criação de peixes pode ser feita de forma integrada com a criação de outros animais como patos, galinhas, gansos, porcos, coelhos, ovelhas, cabras e vacas, 
desde que se considere quais adubos e alimentos utilizar na área de criação, para evitar a poluição da água causada pelo excesso de nutrientes. Na produção extensiva, a reduzida necessidade de mão de obra, menores valores de custeio, menor dependência de insumos externos e menor necessidade de manejo contribuem para a realização da piscicultura voltada à segurança alimentar da família (DOS SANTOS et al., 2014). O cultivo ambientalmente sustentável de animais aquáticos é possível e capaz de gerar produção economicamente viável em uma área relativamente pequena. Medidas como a produção em policultivo em viveiros com baixa renovação de água e o tratamento de efluentes em viveiros cultivados com macrófitas, podem ser suficientes para mitigar o impacto ambiental da piscicultura semi-intensiva (MEDEIROS et al., 2017). 
Figura 5 - A) Lâmina de água na propriedade $\left(\mathrm{m}^{2}\right)$. B) Viveiros por propriedade. C) Produção anual. D) Tipo de cultivo realizado. E) Assistência técnica recebida. F) Capacitação técnica dos produtores

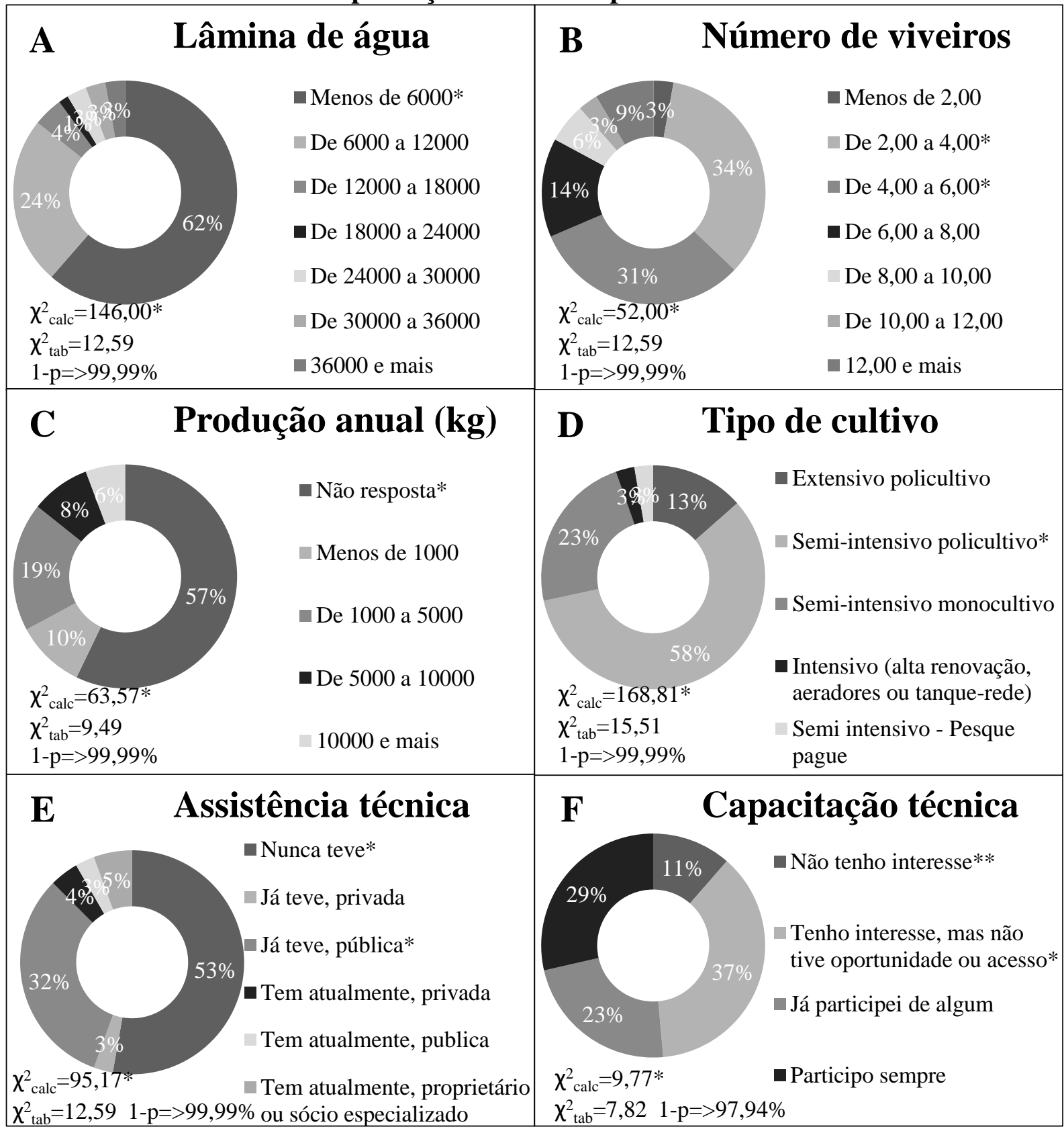

*Resultado diferente, $\mathrm{p}<0,05$.

O problema da comercialização do pescado foi apresentado por $48 \%$ dos piscicultores, que relataram que seu produto é vendido direto ao consumidor em feiras, de porta em porta ou direto na propriedade. Outra parte significativa (33\%) diz não vender o pescado, produzindo somente para autoconsumo. Não seria recomendável incentivar um crescimento de produção sem que sejam abertos canais de escoamento para o pescado. No entanto, se for considerado o uso de pescado como DOI: http://dx.doi.org/10.22295/grifos.v30i53.5987| Edição Vol. 30, Núm. 53, 2021. 
proteína para o consumo da família, a piscicultura é capaz de promover maior segurança alimentar e nutricional (RIBEIRO-NETO et al., 2016).

Os problemas citados pelos produtores, listados na tabela 4, em parte coincidem com a visão das entidades envolvidas na cadeia produtiva. Estão entre os principais problemas mais citados: falta de mercado ou indústria, alto custo de insumos, falta de assistência técnica.

\section{Tabela 4 - Principais problemas observados pelos piscicultores}

\begin{tabular}{lcc}
\hline \multicolumn{1}{c}{ Respostas } & Frequência & Intervalos de confiança \\
\hline Não respondeu & 3 & $0,0 \%<4,3<9,0 \%$ \\
Alto custo de insumos & $26^{*}$ & $25,8 \%<37,1<48,5 \%$ \\
Falta de mercado ou indústria & $26^{*}$ & $25,8 \%<37,1<48,5 \%$ \\
Preço pago pelo pescado & 4 & $0,3 \%<5,7<11,1 \%$ \\
Falha nas políticas públicas & 2 & $0,0 \%<2,9<6,8 \%$ \\
Dificuldade de acesso ao crédito & 1 & $0,0 \%<1,4<4,2 \%$ \\
Falta de assistência técnica & 17 & $14,2 \%<24,3<34,3 \%$ \\
Dificuldade de acesso & 3 & $0,0 \%<4,3<9,0 \%$ \\
Mão de obra & 5 & $1,1 \%<7,1<13,2 \%$ \\
Furto & 2 & $0,0 \%<2,9<6,8 \%$ \\
Alto custo da estrutura & 4 & $0,3 \%<5,7<11,1 \%$ \\
Predadores & 1 & $0,0 \%<1,4<4,2 \%$ \\
Clima & 2 & $0,0 \%<2,9<6,8 \%$ \\
Transporte & 1 & $0,0 \%<1,4<4,2 \%$ \\
\hline
\end{tabular}

*Resultado diferente na coluna, $\mathrm{p}<0,05$.

Apesar das dificuldades e da baixa tecnificação atual, há interesse da maioria em ampliação da área de produção (44\%) e há capacidade de área e água para ampliação (80\%). Um problema que deve ser trabalhado é o desconhecimento quanto à necessidade de licenciamento ambiental da piscicultura, pois $72,9 \%$ dos piscicultores não está regular junto aos órgãos fiscalizadores ambientais.

\section{CONSIDERAÇÕES FINAIS}

Com base nas informações coletadas foi possível observar que a aquicultura, com foco na piscicultura, tem potencial de desenvolvimento na região e já é vista como uma forma de diversificação para pequenas e médias propriedades rurais. As entidades identificadas já tiveram alguma atuação na cadeia aquícola através de políticas públicas específicas, sem o devido planejamento para médio e longo prazo. O resultado foram ações isoladas e sem continuidade, que 
foram insuficientes para o estabelecimento de todos os elos necessários ao setor na região de Laranjeiras do Sul.

O perfil dos aquicultores existentes é de pequenas e médias propriedades familiares, com pequena lâmina de água, mas que tem interesse e possibilidade de ampliação da produção. A atividade é vista como forma de diversificação na maioria dos entrevistados

Observou-se que há um número considerável de produtores que poderia estar comercializando regionalmente, no entanto, a viabilidade da cadeia aquícola depende diretamente da estruturação formal do abate e processamento de pescado. Muitos dos produtores apresentaram interesse em continuar ou ampliar a atividade mas, assim como as entidades entrevistadas, não vislumbram uma forma de levar o seu produto ao mercado.

Como resultado para encaminhamento aos atores envolvidos na cadeia produtiva da região, para um desenvolvimento estruturado e sustentável seria recomendável o apoio às iniciativas privadas individuais e coletivas já existentes para construção e formalização de estruturas de abate.

\section{Agradecimentos}

Agradecimentos especiais aos extensionistas e à gerência da Unidade Regional de Laranjeiras do Sul e das Unidades Municipais do Instituto de Desenvolvimento Rural do Paraná IAPAR-EMATER (IDR-Paraná), assim como às Secretarias de Agricultura, que deram apoio logístico ao desenvolvimento deste levantamento.

Núcleo de estudos em aquicultura com enfoque agroecológico - AquaNEA UFFS/Projeto: Implantação do Centro Vocacional Tecnológico em Agroecologia e produção Orgânica na Região da Cantuquiriguaçu, PR - Chamada MCTI/MAPA/SEAD/MEC/CNPq -21/2016

\section{REFERÊNCIAS}

ALMEIDA, I.F.; FISCHER, J.; SOARES, J.M.F.; HELLEBRANDT, L.M.; ANELLO, L.D.F.S.; WALTER, T. A cadeia produtiva da piscicultura em São Lourenço do Sul/RS. Sinergia - Revista do Instituto de Ciências Econômicas, Administrativas e Contábeis, Rio Grande, v.20, n.2, p.111-126, 2016.

BRUM A.S.; AUGUSTO P.O.M. Ambiente de tarefa: as estratégias da COPACOL (PR) na produção de tilápia em escala industrial pelo sistema vertical integrado. RECC - Revista Eletrônica Científica do CRA-PR, Curitiba, v.3, n.1, p.19-34, 2015. 
CANQUERINO Y.K.; NUNES, P.A.; DA SILVA CARPES, A.M. Estrutura produtiva do território da Cantuquiriguaçu com abordagem insumo-produto para o ano de 2010. Gestão e Desenvolvimento em Revista, Francisco Beltrão, v.1, n.1, p.116-132, 2015.

CHIDICHIMA, A.C.; RAMOS, M.J.; FIORESE, M.L.; FEIDEN, A.; SOUZA FRAGOSO, R.M.M. Indicação geográfica como estratégia de agregação de valor na produção de filé de tilápia: mapeamento da rede de relacionamento no oeste do Paraná. Revista Brasileira de Gestão e Desenvolvimento Regional, Taubaté, v.14, n.5, p.148-159, 2018.

COELHO, L.B.; PAULA, N.M. Políticas públicas e agricultura familiar: uma análise do PRONAF no Território do Cantuquiriguaçu/PR. Revista Grifos, Chapecó, n.45, p.183-203, 2018.

DELGADO, P.R.; BAZOTTI, A.; DE ULHOA CINTRA, A. Jovens rurais e agrícolas no Paraná dimensionamento populacional e perfil socioeconômico. Caderno IPARDES, Curitiba, v.6, n.1, p.1-19, 2016.

DOS SANTOS, I.A.F.; SIEBER, S.S.; FALCON, D.R. Piscicultura de base familiar como estratégia para o desenvolvimento rural: experiências no Estado de Pernambuco. Revista Extensão Rural, DEAER-CCR-UFSM, Santa Maria, v.21, n.1, p.9-26, 2014.

DUTRA, F.M.; BITTENCOURT, F; FEIDEN, A. Perfil aquícola de pequenas propriedades fronteiriças no sudoeste do Paraná/Brasil. Extensio: Revista Eletrônica de Extensão, Florianópolis, v.11, n.17, p.180-189, 2014.

FAO - Food and Agriculture Organization of the United Nations. 2018. The state of world fisheries and aquaculture 2018 - Meeting the sustainable development goals. Roma: FAO. 210p. Disponível em: 〈http://www.fao.org/3/i9540en/I9540EN.pdf>. Acesso em: 27 dez. 2018.

FEIDEN, A.; RAMOS, M.J.; CHIDICHIMA, A.C.; SCHMIDT, C.M.; FIORESE, M.L.; COLDEBELLA, A. A cadeia produtiva da tilápia no oeste do Paraná: uma análise sobre a formação de um arranjo produtivo local. REDES: Revista do Desenvolvimento Regional, Santa Cruz do Sul, v.23, n.2, p.238-263, 2018.

FILIPSKI, M.; BELTON, B. Give a man a fishpond: modeling the impacts of aquaculture in rural economy. World Development, Amsterdã, v.110, p.205-223, 2018.

FONSECA, B.C.; AGUIAR, C.C.; SILVA, E.A.; SANTOS, R.M.; LINHARES, D.P. Apontamentos sobre o processo participativo em cooperativas de Programas de Reativação Econômica: o caso da Coopescabraúna. Revista ELO - Diálogos em extensão, Viçosa, v.6, n.1, p.1-12, 2017.

GLOWKA, R.P.; WEINGARTNER, M.; MUELBERT, B. Produção e comercialização de pescado no município de Laranjeiras do Sul, Paraná. Revista Verde de Agroecologia e Desenvolvimento Sustentável, Pombal, v.13, n.4, p.531-543, 2018.

GRIS, V.G.C.; LAGO, S.M.S.; BRANDALISE, L.T. Sucessão na agricultura familiar: produção cientifica brasileira na área de administração pública e de empresas, ciências contábeis e turismo 
(2004-2016). Revista Extensão Rural, DEAER-CCR-UFSM, Santa Maria, v.24, n.4, p.7-30, 2017.

IPARDES - Instituto Paranaense de Desenvolvimento Econômico e Social. 2018. Cadernos municipais. Curitiba: IPARDES. Disponível em:

$\langle$ http://www.ipardes.gov.br/index.php?pg_conteudo=1\&cod_conteudo=30 $>$. Acesso em: 21 jul. 2018 .

LIMA, F.A.; RODRIGUES, A.P.O; OLIVEIRA-MACIEL, P.; PRYSTHON, A.; VALLADÃOFLORES, R.M.; ARAÚJO-BEZERRA, T. Small-scale fish farming in seasonal ponds in Brazil: technical and economic characterization. Latin American Journal of Aquatic Research, Valparaíso, v.46, n.2, p.314-329, 2018.

MATTE, A.; MACHADO, J.A.D. Tomada de decisão e a sucessão na agricultura familiar no sul do Brasil. Revista de Estudos Sociais, Cuiabá, v.18, n.37, p.130-151, 2016.

MATTE, A.; SPANEVELLO, R.M.; LAGO, A.; ANDREATTA, T. Agricultura e pecuária familiar: (des)continuidade na reprodução social e na gestão dos negócios. Revista Brasileira de Gestão e Desenvolvimento Regional, Taubaté, v.15, n.1, p.19-33, 2019.

MEDEIROS, M.V.; AUBIN, J.; CAMARGO, A.F.M. Life cycle assessment of fish and prawn production: Comparison of monoculture and polyculture freshwater systems in Brazil. Journal of Cleaner Production, Amsterdã, v.156, p.528-537, 2017.

PARANÁ. Secretaria da Agricultura e do Abastecimento. Números da pecuária paranaense Ano 2018. Curitiba: Estado do Paraná. Disponível em:

<http://www.agricultura.pr.gov.br/arquivos/File/deral/nppr.pdf>. Acesso em: $27 \mathrm{dez} .2018 \mathrm{a}$.

PARANÁ. Secretaria da Agricultura e do Abastecimento. 2018. Análise econômica da pesca e aquicultura paranaense - Ano 2018. Disponível em:

<http://www.agricultura.pr.gov.br/modules/conteudo/conteudo.php? conteudo=239 >. Acesso em: 28 dez. 2018 b.

PEIXE BR. Associação Brasileira de Piscicultura. Anuário PEIXE BR da Piscicultura 2019. São Paulo: PEIXEBR, 2019. 147p.

R Core Team. 2018. R: A language and environment for statistical computing. Viena: R Foundation for Statistical Computing. Disponível em: 〈https://www.R-project.org/>. Acesso em: 27 dez. 2018.

RAMOS, M.J.; DE SOUZA FRAGOSO, R.M.; FEIDEN, A. A multi-objective approach for suply chain network design: tilápia pisciculture in Paraná State - Brazil. Journal of Agricultural and Food Industrial Organization, v.17, n.1, p.1-14, 2018.

RIBEIRO-NETO, T.F.; SILVA, A.H.G.; GUIMARÃES, I.M.; GOMES, M.V.T. Piscicultura familiar extensiva no baixo São Francisco, estado de Sergipe, Brasil. Acta of Fisheries and Aquatic Resources, São Cristóvão, v.4, n.1, p.62-69, 2016. 